\title{
Editorial
}

\section{The Limitations of Genetic Testing in Psychiatry}

\author{
Steven L. Dubovsky \\ Department of Psychiatry, State University of New York at Buffalo, Buffalo, N.Y., and Departments of Psychiatry and \\ Medicine, University of Colorado, Denver, Colo., USA
}

Despite the burgeoning number of psychiatric treatments, we still do not know how to predict which one will work best for which patient. The hope that genetic (single gene effects) and genomic (multiple gene effects) testing might be useful for diagnosis and treatment has been encouraged by decreased costs of genome sequencing and studies demonstrating an association between mutations in more than 3,000 genes and specific disease phenotypes $[1-3]$. Are the data as promising in psychiatry as they are in other fields?

\section{Cancer Genomics}

Genetic testing has been most promising in oncology. For example, about $10 \%$ of cases of breast cancer have an autosomal dominant pattern of transmission, most commonly mutations in the tumor suppressor genes BRCA1 and BRCA2 [4]. When BRCA1/2 mutations are found, healthy women are offered a very close follow-up, as well as prophylactic antiestrogen therapy or surgery, yet in one study only $9.5 \%$ of high-risk women even underwent genetic counseling, let alone testing [5]. Breast cancer risk alleles have also been found for p53, PTEN (phosphate and tensin homolog deleted from chromosome 10), STK11, CDH1 and PALB2; however, these genetic factors are rare, and there is not much research on screening pro-

\section{KARGER}

E-Mail karger@karger.com www.karger.com/pps tocols for them [4]. In moderately differentiated breast cancers, which comprise $50 \%$ of breast tumors, gene expression signatures for mitotic index, angiogenic potential, p53 mutational status, and estrogen and progesterone dependence provide better stratification of prognosis than histology [6]. However, despite such advances, there is still not much clear integration between genomics and clinical practice in oncology [7].

\section{Psychiatric Diagnosis}

Numerous markers have been associated with psychiatric disorders, including genes for BDNF (brain-derived neurotrophic factor), FOS (FBJ murine osteosarcoma viral oncogene homolog), COMT, DRD1, DRD2, DISC1, GABABR1 ( $\gamma$-aminobutyric acid B receptor 1), NR4A2 (nuclear receptor subfamily 4, group A, member 2), ADORA2A (adenosine A2a receptor), CACNA1C (calcium channel gene), sirtuin 1, LHPP, 5HTR1A, RNAbinding proteins, and genes for myelination, glutaminergic and GABAergic neurotransmission, oxidative stress, signal transduction, response to the environment, cell survival and proliferation, and cell shrinkage and apoptosis, among others [8-13]. Yet no genetic marker has yet been shown to be useful in prospectively identifying any specific psychiatric disorder [14]. Because genetic predis-
(C) 2016 S. Karger AG Basel

0033-3190/16/0853-0129\$39.50/0
Steven L. Dubovsky, MD

Department of Psychiatry, University at Buffalo 462 Grider Street, Room 1182 Buffalo, NY 14215 (USA)

E-Mail dubovsky@buffalo.edu 
position in psychiatry is thinly distributed over thousands of loci, each contributing a small effect, with considerable overlap of brain systems and shared genetic factors [14], sample size in most association studies has generally been too small to produce meaningful, replicable results $[1,15,16]$. In addition, epigenetic and other factors that alter DNA conformation can determine whether susceptibility genes are expressed or suppressed [10], complicating analyses of the relationship between genotype and phenotype. Even relevant genetic markers can be difficult to interpret because inherited gene factors appear to interact with each other and the environment to contribute to both illness susceptibility and clinical presentation $[17,18]$.

Descriptive diagnoses in psychiatry have multiple domains such as age of onset, constellations of specific symptoms, functioning, comorbidity, and evolution over time that assort differently in different patients in the same category to produce functionally different conditions [19]. Genetic profiles associated with any one of these features are not likely to predict more global diagnoses. If the direct path from genotype to phenotype ends at discrete endophenotypes such as arousal, anhedonia, information processing, stress responses, inflammation and mood, rather than global diagnosis, attempts to link the latter to specific genes are likely to prove frustrating [20-23], just as descriptive diagnoses in psychiatry do not adequately consider important subtypes that exhibit different assortments of features such as age of onset, severity, progression or functioning.

\section{Genetic Pharmacokinetic Studies}

Since cytochrome P450 (CYP450) 1A2, 2D6, 2C9, $2 \mathrm{C} 19$, and $3 \mathrm{~A} 4$ account for $60 \%$ of psychiatric drug metabolism [24], considerable interest has centered on using the CYP450 genotype to predict response to psychotropic medications [3]. However, genotype does not inevitably predict phenotype because multiple copies of a more or less active gene can result in more or less metabolic activity than would be expected from the allele that is identified. In addition, the metabolizer phenotype associated with a particular genotype can be inhibited or enhanced by a number of medications, substances, and foods [2530]. In an open study of 900 patients treated with venlafaxine who were both genotyped and phenotyped for CYP2D6, 4\% were genotypically poor metabolizers, while $27 \%$ were phenotypically poor metabolizers, suggesting that $23 \%$ of patients with other genotypes had converted to a poor metabolizer phenotype as a result of concomitant medications [31].

Even if genotype inevitably predicted phenotype, the correlation is stronger between CYP450 phenotype and drug level than clinical response [32], which is modified by metabolism of most medications by more than one enzyme, lack of linear kinetics and saturable elimination for many drugs, unclear correlations between blood level and response for many medications, and therapeutic windows requiring therapeutic monitoring anyway for some of them [24, 26, 33, 34]. Expression of CYP450 enzymes in the brain, which influences drug effect, may be different from their expression in the blood, or even in the intestine and liver [24].

\section{Drug Transporter Studies}

Drug transporters, including P-glycoprotein (P-gp), organic ion transporters, and multidrug and toxin extrusion proteins, modify the effect of CYP450 phenotype on drug levels and drug action because they influence gastrointestinal absorption, tissue uptake, and renal elimination as well as transport in and out of the brain $[35,36]$. In the iSPOTD (International Study to Predict Optimized Treatment in Depression), two different MDR1 single nucleotide polymorphisms (SNPs) of the gene for P-gp (MDR1 or ABCB1) were associated with better responses either to escitalopram and sertraline or to venlafaxine, but there was no a priori hypothesis, other relevant factors such as drug metabolism, ethnicity, age, specific symptoms, or concomitant illness were not addressed [36], and DNA was collected after results were known rather than prospectively [37].

\section{Pharmacodynamic Studies}

Both a deletion (short polymorphism or s-allele) and an insertion (long polymorphism or l-allele) have been found in the gene (SCL6A4) for the promoter region (5-HTTLPR) of the gene for the serotonin transporter (SERT) [32]. The short polymorphism (s) decreases and the long polymorphism (l) increases SLC6A4 transcription rates, resulting in less or more SERT expression, respectively [32]. Research on the association of the s/s genotype with a lower response rate to serotonin reuptake inhibitors in some ethnic groups has been contradictory [38-40], and even without correction for multiple statistical tests, the SCL6A4 genotype explains at most $5 \%$ of the variance in antidepressant response [30]. Attempts have 
been made to correlate SNPs of the brain-specific voltagegated rectifier potassium channel (Kv11.1-3.1) and the cardiac specific version (Kv11.1-1A) with risperidone treatment response and changes in cardiac conduction, respectively, in schizophrenia [41], but the results have not been robust.

\section{Gene Network Studies}

Because treatment outcome seems to be influenced by multiple genetic polymorphisms, each with a small effect $[3,21]$, research has moved toward analysis of networks of genes in the hope of developing more clinically useful information [42-44]. However, such studies have not produced clinically meaningful results $[43,44]$. The Genome-Based Therapeutic Drugs for Depression (GENDEP; $\mathrm{n}=811$ ) study, a substudy of the Sequenced Treatment Alternatives to Relive Depression (STAR*D; $\mathrm{n}=$ 1,491) study, and the Munich Antidepressant Response Study ( $\mathrm{n}=339)$, did not find any combination of genetic markers that influenced treatment response in depression $[1,44]$. Genome-wide association studies did not reveal any SNPs associated with response or remission of nonbipolar, nonpsychotic, major depressive disorder treated openly with serotonin reuptake inhibitors [45], and the STAR*D study did not reveal any positive genome-wide association or top $25 \mathrm{SNP}$ associations with treatment response [45]. A genome-wide association study from the Clinical Antipsychotic Trials of Intervention Effectiveness (CATIE, $\mathrm{n}=738$ ) did not find any combinations of genetic markers that influenced treatment response in schizophrenia $[1,44]$.

\section{Prospective Treatment Studies}

Only a small number of reports have involved the prospective use of genotyping to make treatment decisions. An open study of 58 depressed inpatients reported that genotyping for $\mathrm{ABCB} 1$ was associated with a shorter hospital stay because patients with the TT/GG genotype were more likely to have an increase in the dose of an antidepressant that was a $\mathrm{P}$-gp substrate, although changing to a non-P-gp substrate did not affect outcome [46]. The study was not randomized, and numerous intervening variables, including pharmacokinetics, comorbidity, and history, were not considered.

Four studies have been supported by the manufacturer of a proprietary survey (GeneSight) of CYP2D6, 2C19,
2C9, and 1A2, SLC6A4, and 5HTR2A genotypes that generates a 'composite report' classifying antidepressants and antipsychotic drugs used in the treatment of depression into three categories: 'use as directed', 'use with caution', and 'use with caution and with more frequent monitoring'. An 8-week open study of 44 patients assigned in a nonrandom manner to treatment guided by the composite report (guided treatment) or nonguided treatment by the same clinicians, who were involved with the product, reported that patients in the guided group were less likely to receive medications in the 'use with caution and with more frequent monitoring' category, presumably because of reluctance by the guided clinicians to prescribe medications that required more monitoring [47]. Although improvement of depression was similar for the first 4 weeks in both groups, a single measure at 8 weeks indicated increased depression scores for the nonguided but not the guided group. No explanation was offered for the final increase in depression scores in the nonguided group, when multiple earlier ratings demonstrated a steady decrease in scores. Improvement in the guided group was not impressive, and it is impossible to know whether comorbid factors, concomitant medications, treatment adherence, patient enthusiasm, substance use, adjunctive psychotherapy, clinician knowledge of treatment condition, and open ratings affected the conduct of treatment or the outcome assessment.

A second open, nonrandomized study conducted by the same group in 227 mildly-moderately depressed patients, 165 of whom completed 8 weeks of treatment, reported that patients in the guided group were twice as likely to respond [48]. Since clinicians reported substantial levels of confidence in the genetic reports, it is possible that they worked more vigorously with patients in the guided group, that patients in the guided group were more adherent with a treatment approach they thought would be more effective, or that they reported better results to please the investigators.

In a double-blind, randomized, controlled trial of GeneSight, 25 depressed patients were assigned to treatment as usual and 26 to guided treatment [49]. Improvement was numerically greater in patients in the guided than in the treatment-as-usual group, but none of the group differences were statistically significant. In a fourth report from the same company [50], 97 patients with a depressive or anxiety disorder treated openly by a single psychiatrist with one of the medications in the genetic survey were followed openly for 1 year. The 9 patients taking at least one medication in the 'use with caution' category had significantly more total health care visits and nonpsy- 
chiatric medical visits than the other subjects and had a higher average cost of care. However, these patients also took more medications than the other subjects, and there was a significant correlation between the number of medications taken and the two outcome variables. When different statistical analyses were performed on the same data (e.g. analysis of variance and t tests), some were significant and some were not, and no correction was made for multiple statistical tests. Although the authors contended that their genetic analysis could save health care costs, this hypothesis was not actually tested. Since no data were available on medical comorbidity and severity of psychiatric illness, the possibility was not considered that the small number of patients in the 'use with caution' category had more health care visits and took more medications because they were sicker psychiatrically or medically.

\section{Gene Expression}

Current genotyping approaches in psychiatry consider the presence or absence of a particular allele or group of alleles, but expression of those genes may be suppressed, modified, or enhanced by a number of factors, including circadian transcription patterns, epistasis (gene interactions), regulatory regions, epigenetic factors, and noncoding RNA [14]. Histone modification and DNA methylation in response to experience, inflammation, the illness, and the medications used to treat it can induce or suppress multiple genes, and genotype itself can affect methylation of regulatory sites that leads to epigenetic changes in brain development [51]. Micro-RNAs and short interfering RNAs are short, noncoding posttranslational regulators of gene expression that target hundreds of mRNA transcripts to influence gene networks $[27,52,53]$. The expression of genes for CYP450 enzymes is altered by promoter methylation, micro-RNAs associated with inflammation and other illnesses [27], and some medications [54], resulting in an altered CYP450 phenotype.

\section{Limitations of Pharmacogenetic Testing in Psychiatry}

No matter how much we may want to translate directly to clinical diagnosis reports of an association between a diagnosis and a genetic marker, the nature of the current level of knowledge does not permit this application. Sample sizes in most existing studies have been too small to produce meaningful, replicable results because of the clinical and genetic heterogeneity of psychiatric disorders [55], and the combined influence of multiple genes, each with a small effect size $[1,15,16]$. Most studies have utilized retrospective or post hoc analyses rather than prospective a priori hypotheses [56], and statistical significance is often inflated by lack of correction for multiple statistical tests [16]. The majority of studies lack replication in independent samples, especially by different investigators [16]. Even robust findings would not be clinically applicable until a prospective study demonstrated their ability to preferentially predict one diagnosis or even clinically relevant feature over another.

Using genotype to predict response to medications is even more problematic. Pharmacogenetic studies have been conducted in normal subjects or patients who are not taking other medications and who do not have other illnesses, limiting extrapolation to most clinical settings $[33,34]$. Most studies do not control for the effect on the expression of CYP450 and other genes of age [27], ethnicity [30], smoking [30,34], and use of substances such as alcohol, hormones, St. John's wort, caffeine, cabbage, and grapefruit juice [30]. Genetic studies of treatment outcome have not measured nonadherence [57], but as the rate of nonadherence increases in any population, statistical power to detect a genotype effect decreases substantially [1]. For medications that are chiral mixtures of enantiomers with different actions, the metabolism of each enantiomer may be by different enzymes [58]. Active metabolites with their own metabolic pathways may enhance or interfere with therapeutic or toxic effects predicted by the presumed metabolism of the parent drug $[59,60]$. In most instances, more than one genetic factor affects drug levels and disposition [3], and interactions between these factors can be difficult to predict.

A clear demonstration of a genotype/blood level relationship in a single dose or 8-week study may not correlate with chronic treatment, in which compensatory changes in secondary metabolic pathways and drug transporters, gene up- or downregulation, saturation pharmacokinetics and other factors may modify the impact of oxidative enzyme polymorphisms on final drug level [24, 59]. With chronic treatment, some psychotropic drug metabolites form complexes with P450 enzymes that alter or even reverse the acute effect on metabolism [25]. Longterm changes in P450 enzymes also occur in the brain, with further unpredictable effects, not only on the substrate drug, but on neurotransmitters and neurosteroids metabolized by the same enzymes on which the medication may act [25]. Another complicating factor is that the 
illness, as well as medications used to treat it, can alter the relationship between pharmacologic genotype and phenotype. For example, many proinflammatory cytokines and acute-phase proteins that are associated with mood and anxiety disorders [61] act on transcription or posttranslational protein modification to downregulate some CYP450 genes and upregulate others [62]. At the same time, suppression of cytokines by antidepressants can alter gene expression in directions that antagonize improvement of depression [25]. The impact of evolution of the illness and its response to different treatments in modifying therapeutic strategies during the course of treatment of cancer is relatively straightforward to study by virtue of methodologies for examining genotype and phenotype of cellular clones, but it is still difficult to develop the correct approach to well-characterized tumors [63]. The absence of such measures in psychiatric diagnoses makes this prospect considerably more difficult.

\section{Where Do We Go from Here?}

Psychiatrists, whose work frequently involves ambiguous clinical problems, and who must often consider contradictory elements of patient presentations and avoid premature closure, can have a remarkably low tolerance for ambiguity, conflict, and delayed gratification when it comes to the latest laboratory study. The hope that pharmacogenetic testing will result in unambiguous 'personalized psychiatry' should not lead to quick adoption of technologies that have not yet been demonstrated to reliably predict a specific course or a need for a specific medication, the choice of which remains largely empirical. After all, genetic associations are statistical, but medical practice is personal [14]. Yet there is tremendous pressure to translate each new report of such associations to our patients, not only from our own need to appear 'scientific' and from industry marketing of proprietary tests, but from the marketing of ideas by thought leaders with an intellectual attachment to the latest conceptualization of genetic causality [64].

It is a continuing challenge to examine new genetic findings critically without applying them immediately in the clinic. When adequately powered studies that address gene number and expression and that control for real-life factors that affect outcome such as comorbidity, polypharmacy, environmental exposure, age, gender, ethnicity, substance use, and treatment adherence emerge [44], clinicians who have not put new information into action before integrating it with emerging knowledge about diagnosis, neurobiology, and the evolution of complex disorders will be ready to apply them effectively.

\section{Disclosure Statement}

Dr. Dubovsky has received research support from Janssen, Otsuka, Sumitomo, Neurocrine, Tower Foundation, Wendt Foundation, Oshei Foundation and Patrick Lee Foundation. The author has no other conflicts of interest to disclose.

\section{References}

1 Malhotra AK, Zhang J-P, Lencz T: Pharmacogenetics in psychiatry: translating research into clinical practice. Mol Psychiatry 2012;17: 760-769.

2 Cox DBT, Platt RJ, Zhang F: Therapeutic genome editing: prospects and challenges. Nat Med 2015;21:121-131.

-3 Trembplay J, Hamet P: Role of genomics on the path to personalized medicine. Metabolism 2013;62:S2-S5.

4 Stuckey AR, Onstad MA: Hereditary breast cancer: an update on risk assessment and genetic testing in 2015. Am J Obstet Gynecol 2015;213:161-165.

5 Bellcross CA, Peipins LA, McCarty FA, Rodriguez JL, Hawkins NA, Hensley Alford S, Leadbetter S: Characteristics associated with genetic counseling referral and BRCA $1 / 2$ testing among women in a large integrated health system. Genet Med 2015;17:43-50.
6 Ivshina AV, George J, Senko O, Mow B, Putti TC, Smeds J, Lindahl T, Pawitan Y, Hall P, Nordgren H, Wong JEL, Liu ET, Bergh J, Kuznetsove VA, Miller LD: Genetic reclassification of histologic grade delineates new clinical subtypes of breast cancer. Cancer Res 2006;66:10292-10301.

7 Anonymous: The future of cancer genomics. Nat Med 2015;21:99.

-8 Le-Niculescu H, Balaraman Y, Patel SD, Ayalew M, Gupta J, Kuczenski R, Shekhar A, Shekhar A, Schork N, Geyer MA, Niculescu $\mathrm{AB}$ : Convergent functional genomics of anxiety disorders: translational identification of genes, biomarkers, pathways and mechanisms. Transl Psychiatry 2011;1:e9.

-9 Carrard A, Salzmann A, Malafosse A, Karege F: Increased DNA methylation status of the serotonin receptor 5HTR1A gene promoter in schizophrenia and bipolar disorder. J Affect Disord 2011;132:450-453.
10 Mill J, Tang T, Kaminsky Z, Khare T, Yazdanpanah S, Bouchard L, Jia P, Assadzadeh A, Flanagan J, Schumacher A, Wang SC, Petronis A: Epigenomic profiling reveals DNAmethylation changes associated with major psychosis. Am J Hum Genet 2008;82:696711.

11 Fullerton JM, Tiwari Y, Agahi G, Heath A, Berk M, Mitchell PB, Schofield PR: Assessing oxidative pathway genes as risk factors for bipolar disorder. Bipolar Disord 2010;12:550556.

12 Hoenicka J, Garrido E, Ponce G, RodriguezJimenez R, Martinez I, Rubio G, Jimenez-Arriero MA, Palomo T: Sexually dimorphic interaction between the DRD1 and COMT genes in schizophrenia. Am J Med Genet 2010;153B:984-954. 
13 Hong CJ, Liou YJ, Bai Y, Chen TT, Wang Y, Tsai SJ: Dopamine receptor D2 gene is associated with weight gain in schizophrenia patients under long-term atypical antipsychotic treatment. Pharmacogenet Genomics 2010; 20:359-366.

14 Li JZ: Circadian rhythms and mood: opportunities for multi-level analyses in genomics and neuroscience. Bioessays 2013;36:305315.

15 Genetics of Personality Consortium: Metaanalysis of genome-wide association studies for neuroticism, and the polygenic association with major depression. JAMA Psychiatry 2015;72:642-650.

16 Gillis NK, Innocenti F: Evidence required to demonstrate clinical utility of pharmacogenetic testing: the debate continues. Clin Pharmacol Ther 2014;96:655-657.

17 Fanous AH, Kendler KS: Genetic heterogeneity, modifier genes, and quantitative phenotypes in psychiatric illness: searching for a framework. Mol Psychiatry 2005;10:6-13.

- 18 Patel SD, Le-Niculescu H, Koller DL, Green SD, Lahiri DK, McMahon FJ, Nurnberger JIJ, Niculescu AB: Coming to grips with complex disorders: genetic risk prediction in bipolar disorder using panels of genes identified through convergent functional genomics. Am J Med Genet 2010;153B:850-877.

$\checkmark 19$ Fava GA, Guidi J, Grandi S, Hasler G: The missing link between clinical states and biomarkers in mental disorders. Psychother Psychosom 2014;83:136-141.

20 Van Borkulo C, Boschioo L, Borsboom D, Pennix BWJH, Waldorp LJ, Schoevers RA: Association of symptom network structure with the course of longitudinal depression. JAMA Psychiatry 2015;72:1219-1226.

- 21 Keers R, Aitchison KJ: Pharmacokinetics of antidepressant response. Expert Rev Neurother 2011;11:101-125

22 Domschke K: Clinical and molecular genetics of psychotic depression. Schizophr Bull 2013; 39:766-775.

23 Fabbri C, Porcelli S, Serretti A: From pharmacogenetics to pharmacogenomics: the way toward the personalization of antidepressant treatment. Can J Psychiatry 2014;59:62-75.

-24 Preissner SC, Hoffmann MF, Preissner R, Dunkel M, Gewiess A, Preissner S: Polymorphic cytochrome P450 enzymes (CYPs) and their role in personalized therapy. PLoS One 2013;8:e82562.

25 Wladyslawa AD: The influence of long-term treatment with psychotropic drugs on cytochrome P450: the involvement of different mechanisms. Expert Opin Drug Metab Toxicol 2005;1:203-217.

26 Crews KR, Gaedigk A, Dunnenberger HM, Leeder JS, Klein TE, Caudle KE, Haidar CE, Shen DD, Callaghan JT, Sadhasivam S, Prows CA, Kharasch ED, Skaar TC: Clinical Pharmacogenetics Implementation Consortium guidelines for cytochrome P450 2D6 genotype and codeine therapy: 2014 update. Clin Pharmacol Ther 2014;95:376-382.
Zanger UM, Klein K, Thomas M, Rieger JK, Tremmel R, Kandel BA, Klein BA, Klein M, Magdy T: Genetics, epigenetics, and regulation of drug-metabolizing cytochrome p450 enzymes. Clin Pharmacol Ther 2014;95:258-261.

28 Misaka S, Kawabe K, Onoue S, Werba JP, Giroli M, Tamaki S, Kan T, Kimura J, Watanabe $\mathrm{H}$, Yamada S: Effects of green tea catechins on cytochrome P450 2B6, 2C8, 2C19, 2D6 and $3 \mathrm{~A}$ activities in human liver and intestinal microsomes. Drug Metab Pharmacokinet 2013; 28:244-249.

29 Yamasaki I, Yamada M, Uotsu N, Teramoto $S$, Takayanagi R, Yamada Y: Inhibitory effects of kale ingestion on metabolism by cytochrome P450 enzymes. Biomed Res 2012;33: 235-242.

30 Jones DS, Perlis RH: Pharmacogenetics, race, and psychiatry: prospects and challenges. Harvard Rev Psychiatry 2006;14:92-108.

31 Preskorn SH, Kane CP, Lobello K, Nichols AI, Fayyad R, Buckley G, Focht K, Guico-Pabia CJ: Cytochrome P450 2D6 phenoconversion is common in patients being treated for depression: implications for personalized medicine. J Clin Psychiatry 2013;74:614-621.

32 Alter CN, Hornberger J, Shewade A, Cruz V, Garrison J, Mrazek D: Clinical validity of cytochrome P450 metabolism and serotonin gene variants in psychiatric pharmacotherapy. Int Rev Psychiatry 2013;25:509-533.

33 De Leon J, Arranz GR: Pharmacogenetic testing in psychiatry: a review of features and clinical realities. Clin Lab Med 2008;28:599-617.

34 Kirchheiner J, Brosen K, Dahl ML, Gram LF, Kasper S, Roots I, Sjoqvist F, Spina E, Brockmoller J: CYP2D6 and CYP2C19 genotypebased dose recommendations for antidepressants: a first step towards subpopulation-specific dosages. Acta Psychiatr Scand 2001;104: 173-192.

-35 Rosenhagen MC, Uhr M: The clinical impact of ABCB1 polymorphisms in the treatment of psychiatric diseases. Curr Pharm Des 2011; 17:2843-2851.

36 Goswami S, Yee SW, Stocker S, Mosley JD, Kubo M, Castro R, Mefford JA, Wen C, Liang X, Witte J, Brett C, Maeda S, Simpson MD, Hedderson MM, Davis RL, Roden DM, Giacomini KM, Savic RM: Genetic variants in transcription factors are associated with the pharmacokinetics and pharmacodynamics of metformin. Clin Pharmacol Ther 2014;96: 370-370.

37 Schatzberg AF, DeBattista C, Lazzeroni LC, Etkin A, Murphy GM, Williams LM: ABCB1 genetic effects on antidepressant outcomes: a report from the iSPOT-D trial. Am J Psychiatry 2015;172:751-759.

38 Porcelli S, Fabbri C, Serretti A: Meta-analysis of serotonin transporter gene promoter polymorphism (5-HTTLPR) association with antidepressant efficacy. Eur Neuropsychopharmacol 2012;22:239-258.
9 Taylor MJ, Sen S, Bhagwagar Z: Antidepressant response and the serotonin transporterlinked polymorphic region. Biol Psychiatry 2010;68:536-543

40 Kang HJ, Kim JM, Stewart R, Kim SY, Bae KY, Kim SW, Shin MG, Yoon IS: Association of SLC6A4 methylation with early adversity, characteristics and outcomes in depression. Prog Neuropsychopharmacol Biol Psychiatry 2013;44:23-28.

41 Heide J, Zhang F, Bigos KL, Mann SA, Carr VJ, Weickert CS, Green MJ, Weinberger DR, Vandenberg JI: Differential response to risperidone in schizophrenia patients by KCNH2 genotype and drug metabolizer status. Am J Psychiatry 2016;173:53-59.

42 Costa e Silva JA: Personalized medicine in psychiatry: new technologies and approaches. Metabolism 2013;62:S40-S44.

43 Singh AB, Bousman CA, Ng C, Berk M: Antidepressant pharmacogenetics. Curr Opin Psychiatry 2014;27:43-51.

44 Hamilton SP: The promise of psychiatric pharmacogenomics. Biol Psychiatry 2015;77: 29-35.

45 Ji Y, Biernacka JM, Hebbring S, Jenkins GD, Batzler A, Snyder KA, Drews MS, Desta Z, Flockart D, Mushiroda T, Kubo M, Nakamura Y, Kamatani N, Schaid D, Weinshilboum RM, Mrazek D: Pharmacogenomics of selective serotonin reuptake inhibitor treatment for major depressive disorder: genome-wide associations and functional genomics. Pharmacogenomics J 2013;13:456463.

46 Breitenstein B, Scheuer S, Pfister H, Uhr M, Lucae S, Holsboer F, Ising M, Bruckl T: The clinical application of $\mathrm{ABCB} 1$ genotyping in antidepressant treatment: a pilot study. CNS Spectr 2014;19:165-175.

47 Hall-Flavin DK, Winner JG, Allen J, Jordan JJ, Nesheim RS, Snyder KA, Drews MS, Eisterhold LL, Biernacka JM, Mrazek D: Using a pharmacogenomic algorithm to guide the treatment of depression. Transl Psychiatry 2012;2:e172.

48 Hall-Flavin DK, Winner JG, Allen J, Carhart JM, Proctor B, Snyder KA, Drews MS, Eisterhold LL, Geske J, Mrazek D: Utility of integrated pharmacogenomic testing to support the treatment of major depressive disorder in a psychiatric outpatient setting. Pharmacogenet Genomics 2013;23:535-548.

${ }_{49}$ Winner JG, Carhart JM, Alter CN, Allen J, Dechairo BM: A prospective, randomized, double-blind study assessing the clinical impact of integrated pharmacogenomic testing for major depressive disorder. Discov Med 2013;16:219-227.

50 Winner JG, Allen J, Altar CA, Spahic-Mihajlovic A: Psychiatric pharmacogenomics predicts health resource utilization of outpatients with anxiety and depression. Transl Psychiatry 2013;3:e242. 
-51 Hannon E, Spiers H, Viana J, Pidsley R, Burrage J, Murphy TM, Troakes $\mathrm{C}$, Turecki G, O’Donovan MC, Schalkwyk LC, Bray NJ, Mill J: Methylation QTLS in the developing brain and their enrichment in schizophrenia risk loci. Nat Neurosci 2016;19:48-54.

52 Geaghan M, Cairns MJ: MicroRNA and posttranscriptional dysregulation in psychiatry. Biol Psychiatry 2015;78:231-239.

53 Xu Q, Wu X, Xiong Y, Xing Q, He L, Qin S: Pharmacogenomics can improve antipsychotic treatment in schizophrenia. Front Med 2013;7:180-190.

54 Gardiner E, Carroll A, Tooney PA, Cairns MJ Antipsychotic drug-associated gene-miRNA interaction in T-lymphocytes. Int J Neuropsychopharmacol 2014;17:929-943.

-55 Le-Niculescu H, Kurian SM, Yehyawi N, Dike C, Patel SD, Edenberg HJ, Tsuang MT, Salomon DR, Nurnberger JIJ, Niculescu AB: Identifying blood biomarkers for mood disorders using convergent functional genomics. Mol Psychiatry 2009;14:156-174.
56 Janssens ACJW, Deverka PA: Useless until proven effective: the clinical utility of preemptive pharmacogenetic testing. Clin Pharmacol Ther 2014;96:652-654.

57 Melfi CA, Chawla AJ, Croghan TW, Hanna MP, Kennedy S, Sredl K: The effects of adherence to antidepressant treatment guidelines on relapse and recurrence of depression. Arch Gen Psychiatry 1998;55:1128-1132.

58 Crettol S, de Leon J, Hiemke C, Eap CB: Pharmacogenomics in psychiatry: from therapeutic drug monitoring to genomic medicine. Clin Pharmacol Ther 2014;95:254-257.

59 Kirchheiner J, Nickchen K, Bauer M, Wong M-L, Roots I, Brockmoller J: Pharmacogenetics of antidepressants and antipsychotics: the contribution of allelic variations to the phenotype of drug response. Mol Psychiatry 2004;9:442-473.
60 Seeringer A, Kirchheiner J: Pharmacogenetics-guided dose modifications of antidepressants. Clin Lab Med 2008;28:619-626.

61 Young JJ, Bruno D, Pomara N: A review of the relationship between proinflammatory cytokines and major depressive disorder. J Affect Disord 2014;169:15-20.

62 Harvey RD, Morgan ET: Cancer, inflammation, and therapy: effects on cytochrome p450-mediated drug metabolism and implications for novel immunotherapeutic agents. Clin Pharmacol Ther 2014;96:449-457.

63 Michor F, Beal K: Improving cancer treatment via mathematical modeling: surmounting the challenges is worth the effort. Cell 2015;163:1059-1063.

64 Dubovsky SL, Dubovsky AN: Psychotropic Drug Prescriber's Survival Guide: Ethical Prescribing in the Age of Big Pharma. New York, Norton, 2007. 